BMJ Nutrition, Prevention \& Health

\section{Association between severity of COVID-19 symptoms and habitual food intake in adult outpatients}

To cite: Salazar-Robles $\mathrm{E}$, Kalantar-Zadeh K, Badillo $\mathrm{H}$, et al. Association between severity of COVID-19 symptoms and habitual food intake in adult outpatients. BMJ Nutrition, Prevention \& Health 2021;4:e000348. doi:10.1136/ bmjnph-2021-000348

- Additional supplemental material is published online only. To view, please visit the journal online (http://dx.doi.org/10. 1136/bmjnph-2021-000348).

For numbered affiliations see end of article.

Correspondence to Professor Kourosh KalantarZadeh, Chemical Engineering, University of New South Wales, Sydney, NSW 2052, Australia; k.kalantar-zadeh@unsw.edu. au and

Dr Claudia Lerma; lermag@unam.mx

Received 29 July 2021 Accepted 5 0ctober 2021 Published Online First 12 November 2021

Check for updates

(C) Author(s) (or their employer(s)) 2021. Re-use permitted under CC BY-NC. No commercial re-use. See rights and permissions. Published by BMJ.

\section{ABSTRACT}

Objective To evaluate the association between habitual frequency of food intake of certain food groups during the COVID-19 pandemic and manifestations of COVID-19 symptoms in adult outpatients with suspected SARSCoV-2 infection.

Design We included 236 patients who attended an outpatient clinic for suspected COVID-19 evaluation. Severity of symptoms, habitual food intake frequency, demographics and Bristol chart scores were obtained before diagnostic confirmation with real-time reverse transcriptase PCR using nasopharyngeal swab.

Results The results of the COVID-19 diagnostic tests were positive for 103 patients (44\%) and negative for 133 patients $(56 \%)$. In the SARS-CoV-2-positive group, symptom severity scores had significant negative correlations with habitual intake frequency of specific food groups. Multivariate binary logistic regression analysis adjusted for age, sex and occupation confirmed that SARSCoV-2-positive patients showed a significant negative association between having higher symptom severity and the habitual intake frequency of 'legumes' and 'grains, bread and cereals'.

Conclusions Increase in habitual frequency of intake of 'legumes', and 'grains, bread and cereals' food groups decreased overall symptom severity in patients with COVID-19. This study provides a framework for designing a protective diet during the COVID-19 pandemic and also establishes a hypothesis of using a diet-based intervention in the management of SARS-CoV-2 infection, which may be explored in future studies.

\section{INTRODUCTION}

Diet is significant for health and can be either a protective or a risk factor for the development of chronic diseases such as type 2 diabetes mellitus, ${ }^{1}$ hypertension, ${ }^{2}$ other endocrinological diseases ${ }^{3}$ and renal diseases. ${ }^{4}$ Diet also plays a major role in the pathogenesis of infectious respiratory diseases, such as tuberculosis ${ }^{5}$ and viral infections (ie, rhinovirus, influenza and adenovirus). ${ }^{6}$ A complex and multilayer interaction between habitual and temporal food intake, collective food consumption pattern, and health status shapes

\section{What this paper adds}

We tested the hypothesis of the effect of diet on SARS-CoV-2 infection symptom severity

- We evaluated the association between the habitual frequency of certain food groups and the manifestations of COVID-19 symptoms' severity in adult outpatients

- We found that an increase in the habitual frequency of intake of 'legumes', and 'grains, bread and cereals' food groups may reduce the overall symptom' severity in patients with COVID-19

immunological and physiological status, ${ }^{7-9}$ especially in response to viral infections. As such, links can also be potentially found in infections caused by coronavirus (COVID19). Both energy restrictions and high caloric diets can disrupt the body immune response against viral respiratory infections. ${ }^{10}$ There are also recent reports that suggest specific food groups can modulate the severity of SARS-CoV-2 infection. ${ }^{11}$ Additionally, the COVID-19 pandemic has brought substantial changes to people's dietary habits and community food quality and availability. ${ }^{12}$ These changes are different for every region and also for individuals, ${ }^{13} 14$ which in turn can influence the immune system of the population in response to COVID-19 infection.

Nutritional status is directly associated with inflammation and consequently with immune response. ${ }^{10}$ The symptoms of the COVID-19 syndrome are variable among individuals, and the reasons that such differences are seen remain confounded ${ }^{9}$ but could potentially include diet. Besides respiratory symptoms, gastrointestinal manifestations such as nausea, vomiting, abdominal pain and diarrhoea are also relatively common in SARSCoV-2 infections. ${ }^{15}$ However, the relations between this set of symptoms and the severity of clinical features are still unclear. ${ }^{16}$ It has 
been proposed that SARS-CoV-2 infection may cause microbiome dysbiosis, which influences gastrointestinal physiology and immunological balances. ${ }^{15}$

Recent studies have begun to unravel the links between dietary microbiota modulation and host immunity. Western-style diets profoundly affect the gut microbiome configuration and impact host immunological balances. ${ }^{17}$ Altogether, the type of diet highly influences the composition of the microbiota, which in turn modifies the host health. ${ }^{18}$ This intricate interaction is likely to be disrupted by SARS-CoV-2 infections and may alter the clinical course of the syndrome beyond gastrointestinal symptoms. ${ }^{19}$ $\mathrm{Kim}^{20}$ argued that unhealthy gut microbiomes might be the underlying reason for the predisposition of normal individuals to severe COVID-19. Changes in diet, especially the amount of indigestible food components such as dietary fibres, change the gut microbiota composition. David $e t a l^{21}$ found that even short-term consumption of meals composed entirely of animal or plant products alters the microbiota structure and overwhelms interindividual differences in microbial gene expression.

A balanced nutrition, favouring the immune response, is essential to prevent and manage viral infections. ${ }^{10}$ Obesity, in which diet plays a major role, is associated with higher mortality rate in patients with COVID-19. ${ }^{22}$ The high prevalence of these risk factors was suggested to be driven by increased consumption of typical contemporary diets with high amounts of saturated fats, sugar and refined carbohydrates, and low levels of fibre, unsaturated fats and antioxidants. ${ }^{23}$ Detrimental changes in diet can cause obesity and concurrent alterations in the human gut microbiota composition. ${ }^{24}$ In Mexico, where the study presented in this paper was conducted, $72.5 \%$ of adults are either obese and overweight, and such a high prevalence has been characterised by an excessive intake of discretionary foods. ${ }^{25}$ Moreover, during the lockdown period around the globe, meal patterns became unhealthier (ie, less fresh food, excessive eating, snacks between meals and deviation from the normal number of meals) ${ }^{26} \mathrm{~A}$ few reports have proposed that diet might explain some of the differences in mortality rates among countries. ${ }^{27}$ Although there are differences in dietary patterns, unbalanced diets are a health threat worldwide and affect death rates and quality of life. ${ }^{28}$ Such information may point to an association between food intake and clinical features of COVID-19.

The purpose of this work is to evaluate if there is a relationship between habitual intake of certain food groups and manifestations of COVID-19 symptoms in adult outpatients with suspected SARS-CoV-2 infection.

\section{METHODS}

\section{Study protocol and participants}

This cross-sectional study included 236 patients who attended an outpatient clinic for COVID-19-related evaluation in the Alvaro Obregon borough of Mexico City. The study was conducted in a period between October 2020 and January 2021. Informed consent was obtained from all participants.

All study participants were suspected cases, that is, patients who attended the clinic for either medical attention for COVID-19-related symptoms (fever, cough, odynophagia, dyspnoea, irritability, diarrhoea, chest pain, shivers, headache, myalgia, arthralgia, malaise, rhinorrhoea, polypnoea, vomiting, abdominal pain, conjunctivitis, cyanosis, anosmia and dysgeusia) or a clinical evaluation due to contact with SARS-CoV-2-positive individuals. All clinical variables were obtained during the medical interviews of the subjects with suspected cases of the viral respiratory disease. Demographic and clinical data were noted on the medical records. Patients were eligible for participation in the study if they were 18 years of age or older and capable of filling in the questionnaires. Exclusion criteria were major psychiatric or medical problems (reported on the health history), pregnancy or breast feeding. Patients were asked if they wanted to participate in the study; if the answer was positive the questionnaire was administered. Severity of symptoms and habitual food intake frequency were assessed through a questionnaire given after the clinical evaluation and before the COVID-19 diagnostic test (as detailed in the following section).

\section{Sample size}

We selected a Pearson correlation of 0.4 as the minimum to be considered relevant between food intake frequency of any food group and the overall symptom severity score. Considering a unilateral $\alpha$ error of 0.05 and a statistical power of 0.9 , the minimum number of participants is 62 . The national ratio of positive SARS-CoV-2 tests was 1:2 at the time of this study; thus, at least 186 patients were planned to be recruited during the sampling period.

\section{Diagnostic test for SARS-CoV-2 infection}

The diagnostic test for SARS-CoV-2 infection was performed using real-time PCR technique. ${ }^{29}$ Collection and analysis of the samples for diagnosis of COVID-19 were carried out by following the Standardized Guideline for Epidemiological and Laboratory Surveillance of Viral Respiratory Disease issued by the Ministry of Health, Mexico. ${ }^{30} \mathrm{~A}$ confirmed case (positive test) was a person who had a laboratory-confirmed diagnosis of COVID-19 according to the National Network of Public Health Laboratories recognised by the Institute for Epidemiological Diagnosis and Reference. Clinical evaluation and sampling procedures were carried out following the preventive measures for managing patients with viral respiratory disease for health personnel. ${ }^{30}$ Sampling was of a pharyngeal or nasopharyngeal exudate type according to the procedure described in the 'Technical details of diagnostic tests for SARS-CoV-2 infection' section of the online supplemental material. ${ }^{30}$ Patients' clinical information was entered into the epidemiological surveillance system with an identification number for follow-up of case and notification of test results through the health centre 
where the sample was taken, and the case was evaluated. ${ }^{30}$ Test results were communicated to each patient by phone within 1-3 days after performing the test.

\section{Assessment of habitual frequency of food intake}

A habitual Food Frequency Questionnaire (FFQ) was designed in a web-based online form to collect information on the dietary intake of adults during the previous 3 months. It was a qualitative FFQ. The first section included 96 food items divided into 10 food groups, representing Mexico's most commonly consumed foods. The FFQ was adapted from the Mexican FFQ 'Frecuencia de consumo de alimentos de adolescentes y adultos 12 años o más ${ }^{31}$; this FFQ has been validated in Mexico by the National Institute of Public Health for collecting data during the National Health and Nutrition Survey 20182019. A complete list of the food items is found in online supplemental table S1.

The FFQ food groups were divided into the following categories: 'milk and milk products', 'fruit', 'vegetables', 'animal products', 'legumes', 'grains, bread and cereals', 'corn-based products', 'beverages', 'fats and oil', and 'hot peppers and sauce'. Participants were asked to report the usual frequency of food item consumption in the following specified categories: 'never', 'once a month', 'two or three times a month', 'once a week', 'two to three times a week', 'four to six times a week', 'one time per day', and 'two times or more per day', which were scored from 0 to 7 in the same order.

\section{Assessment of symptom severity}

We developed a symptom severity scale for self-completion that assessed the severity of symptoms as perceived by the outpatients. ${ }^{32} 33$ Symptom severity can serve as a complementary measure of respiratory disease impact for individuals seeking care in outpatient settings. ${ }^{34}$ Symptom severity was assessed using a subjective self-rating scale of 11 symptoms: 'fever', 'cough', 'cold chills', 'body pain', 'fatigue', 'difficulty of breathing', 'headache', 'sore throat', 'loss of taste', 'nausea' and 'diarrhea'. Participants rated each of their symptoms on a Likert scale from 0 to 10 , where 0 was 'I don't have the symptom', 5 was 'the symptom is moderate' and 10 was 'the symptom is severe'. An appetite score was also applied using a Likert scale, where 1 was 'very bad' and 5 was 'very good'. Patients were asked to rate their taste on a 6-point scale as "no taste', 'very bad', 'bad', 'regular', 'good' and 'very good' and scored from 0 to 6 points in the same order. Additionally, patients were asked to match the closest appearance of their stool using the Bristol chart. ${ }^{35}$

\section{Statistical analysis}

Qualitative variables were described as absolute frequency and percentage and were compared between groups by $\chi^{2}$ or exact Fisher's test. In all discrete and continuous quantitative variables, normal distribution was tested with Kolmogorov-Smirnov test. Variables with normal distribution were described as mean $\pm \mathrm{SD}$ and were compared between groups by Student's t-test for independent groups (with variances equal or unequal according to an $F$ test). Otherwise, the variables were described as median (25th-75th percentile) and were compared between groups by Mann-Whitney U test. Spearman's correlation analyses were performed between the total number of symptoms and the total food intake groups. Multivariate binary logistic regression analyses were performed to assess the association between having higher severity of symptoms (as a dependent variable) and frequency of food intake of each food group, age, sex and occupation (as independent variables). The results are shown as OR with $95 \%$ CI.

\section{RESULTS}

The diagnostic test was positive for SARS-CoV-2 in 103 patients (44\%) and negative in $133(56 \%)$. There were no significant differences between the groups in terms of sociodemographic characteristics (age, sex, occupation and body mass index (BMI)) as well as comorbidities (smoking, hypertension or diabetes mellitus), as shown in table 1.

The results of the analysis of symptom severity and food intake frequency are shown in table 2. Compared with patients with a negative test result, those with a positive test result had a significantly higher sum of symptoms' severity. The median for habitual frequency of food intake was similar for patients with positive and negative test results in all food groups.

Given that symptom severity score was higher in outpatients with positive test results for COVID-19 compared with those with negative test results, we stratified the symptom severity score according to the median score of 18 points (table 2) and compared the sociodemographic characteristics and comorbidities between the two groups by test results stratified by symptom severity score (table 3 ). All characteristics were similar between the subgroups, except for an older age in the subgroup with negative test and symptom severity score $\leq 18$ (compared with those with positive test and symptom severity score $\leq 18$, indicated by $*$ in table 3 ). Additionally, occupation was different between the subgroups with negative test results and symptom severity score $>18$ and those with positive test results and symptom severity score $>18$ (indicated by $\dagger$ in table 3 ).

As the first approach to investigate the relationships between symptoms' severity and habitual food frequency intake, we performed bivariate correlation analyses. Table 4 shows the Spearman's correlation analysis between symptom severity sum scores and food intake frequency. Online supplemental figure S1 shows the scatter-dot plots of the symptom severity sum score as a function of frequency of food intake of several food groups. In the group with a positive test result, symptom severity sum scores had significant negative correlations with frequency of intake of (1) 'milk and milk products', (2) 'legumes', (3) 'grains, bread and cereals', and (4) 'fats 
Table 1 Sociodemographic characteristics and comorbidities of the study population

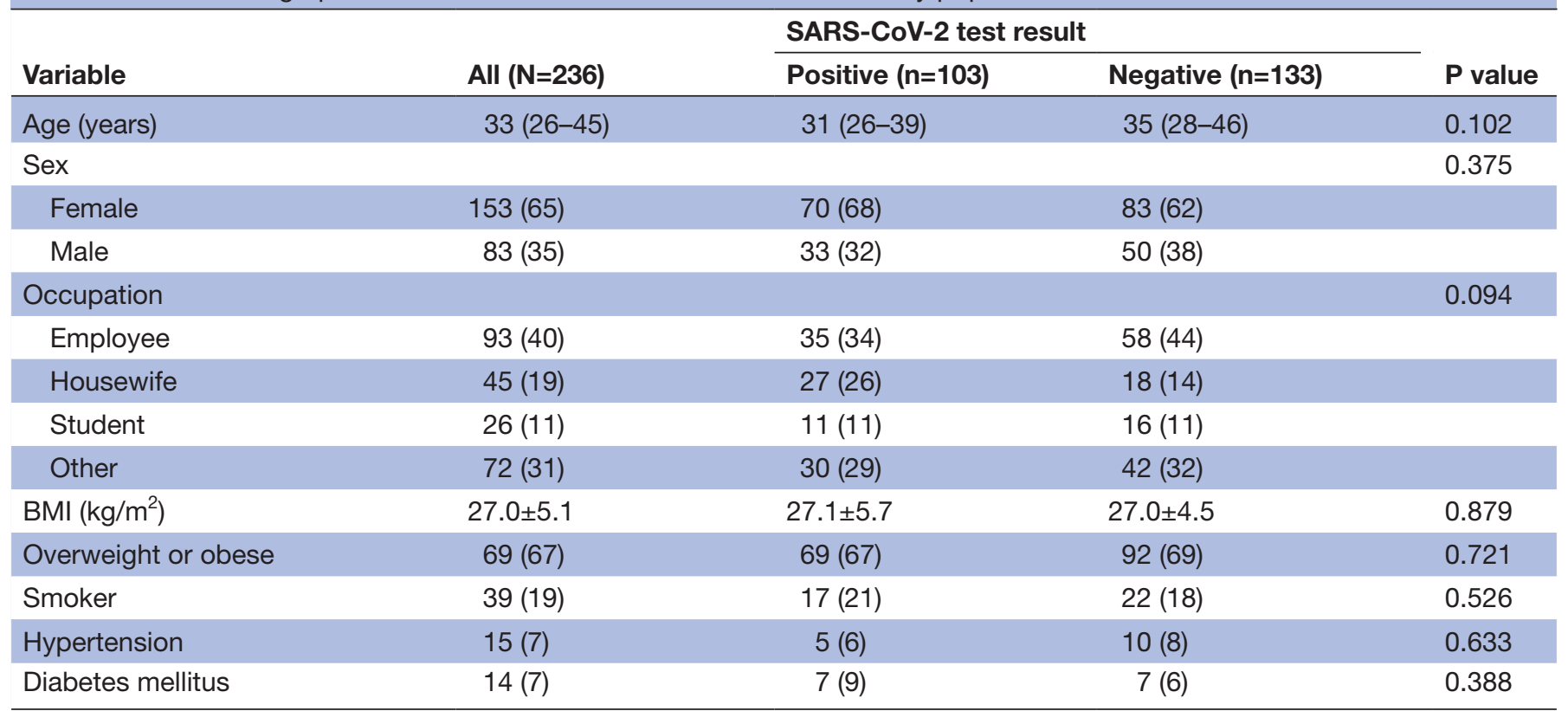

Data are shown as absolute value (percentage), mean \pm SD or median (25th-75\% percentile).

BMI, body mass index.

and oil'. In contrast, the group with a negative test result had significant positive correlations between symptom severity sum score and frequency of intake of (1) 'beverages' and (2) 'hot peppers and sauce'.

Considering that age could be a confounding variable, we also explored the bivariate correlations between food frequency intake and age (table 4 ). The group with positive tests showed significant negative correlations between age and intake of (1) 'milk and milk products', (2) 'fruit', and (3) 'beverages'. The group with negative tests showed significant correlations (positive or negative) between age and frequency of intake of most food groups: (1) 'vegetables', (2) 'animal products', (3) 'legumes', (4) 'grains, bread and cereals', (5) 'beverages', and (6) 'hot peppers and sauce'.

The association between the habitual food intake and higher severity of symptoms (ie, symptom severity score $>18$ points) was estimated by a binary logistic regression for each food group (as independent variable), with univariate models (ie, basic models) in both groups (positive test or negative test group) (table 5). Then, age, sex and occupation were introduced in each basic model to constitute a multivariate binary regression analysis that measures the association between food intake of each group and having a high severity of symptoms, with adjustment for the confounding variables.

Table 2 Symptom severity sum score and food intake frequency of the study population

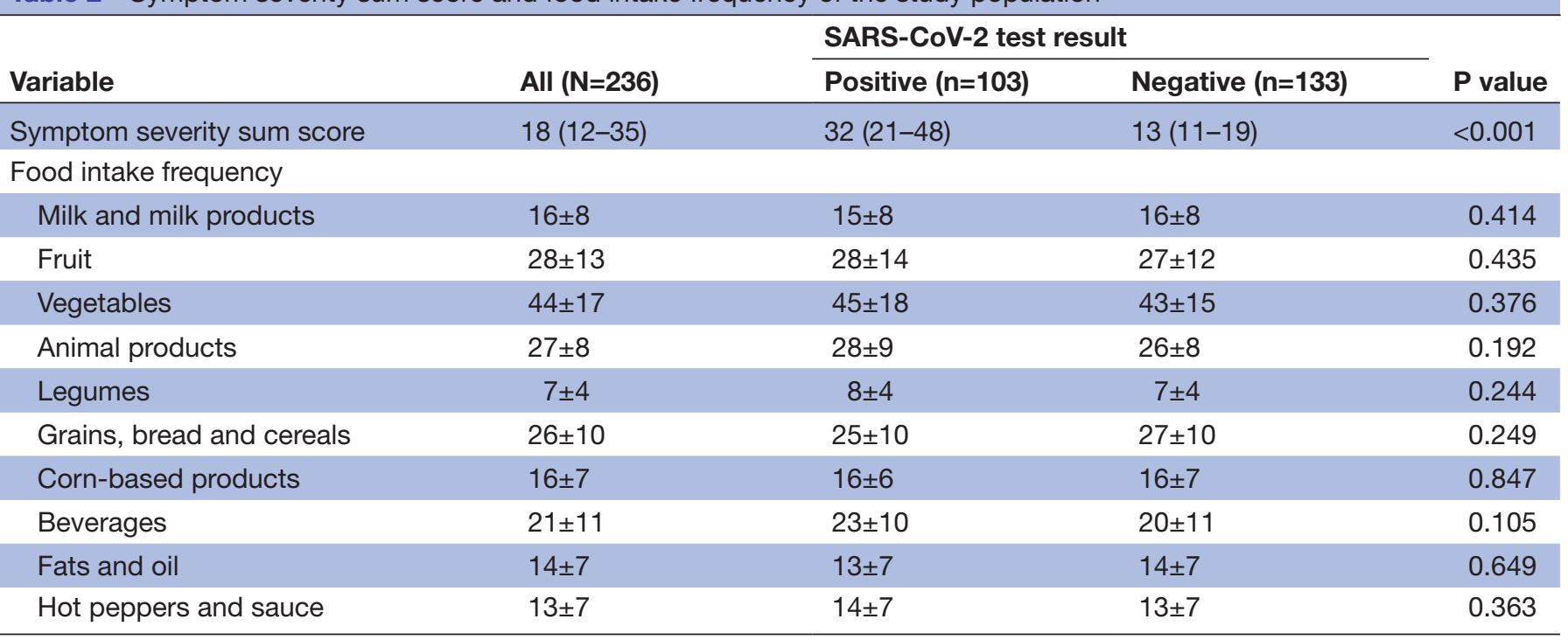

Data are shown as mean \pm SD or median (25th-75th percentile). 
Table 3 Sociodemographic characteristics and comorbidities of the study population stratified by severity of symptoms

\begin{tabular}{|c|c|c|c|c|c|c|}
\hline \multirow[b]{3}{*}{ Variable } & \multirow{2}{*}{\multicolumn{2}{|c|}{ All (N=236) }} & \multicolumn{4}{|c|}{ SARS-CoV-2 test result } \\
\hline & & & \multicolumn{2}{|c|}{ Positive ( $n=103$ ) } & \multicolumn{2}{|c|}{ Negative $(n=133)$} \\
\hline & $\begin{array}{l}\text { Symptom } \\
\text { severity } \\
\text { score } \leq 18\end{array}$ & $\begin{array}{l}\text { Symptom } \\
\text { severity } \\
\text { score >18 }\end{array}$ & $\begin{array}{l}\text { Symptom } \\
\text { severity } \\
\text { score } \leq 18\end{array}$ & $\begin{array}{l}\text { Symptom } \\
\text { severity } \\
\text { score }>18\end{array}$ & $\begin{array}{l}\text { Symptom } \\
\text { severity } \\
\text { score } \leq 18\end{array}$ & $\begin{array}{l}\text { Symptom } \\
\text { severity } \\
\text { score >18 }\end{array}$ \\
\hline Age (years) & $34(26-46)$ & $32(27-44)$ & $28(22-38)$ & $32(26-44)$ & $36(28-46)^{*}$ & $32(27-45)$ \\
\hline \multicolumn{7}{|l|}{ Sex } \\
\hline Female & $72(61)$ & $81(69)$ & $14(70)$ & $56(68)$ & $58(59)$ & $25(74)$ \\
\hline Male & 47 (39) & $36(31)$ & $6(30)$ & 27 (33) & $41(41)$ & $9(26)$ \\
\hline \multicolumn{7}{|l|}{ Occupation } \\
\hline Employee & $56(47)$ & $37(32)$ & $8(40)$ & $27(33)$ & $48(49)$ & $10(29) \dagger$ \\
\hline Housewife & $19(16)$ & $26(22)$ & $4(20)$ & $23(28)$ & $15(15)$ & $3(9) \dagger$ \\
\hline Student & $13(11)$ & $13(11)$ & $5(25)$ & $6(7)$ & $8(8)$ & $7(21) \dagger$ \\
\hline Other & $31(26)$ & $41(35)$ & $3(15)$ & $27(33)$ & $28(8)$ & $14(41) \dagger$ \\
\hline BMI $\left(\mathrm{kg} / \mathrm{m}^{2}\right)$ & $26.8 \pm 4.8$ & $27.2 \pm 5.3$ & $27.0 \pm 7.6$ & $27.1 \pm 5.2$ & $26.8 \pm 4.0$ & $27.4 \pm 5.8$ \\
\hline Overweight or obese & $79(66)$ & $82(70)$ & $11(55)$ & $58(70)$ & $68(69)$ & $24(70)$ \\
\hline Smoker & $17(15)$ & $22(23)$ & $4(21)$ & $13(21)$ & $13(14)$ & $9(28)$ \\
\hline Hypertension & $6(5)$ & $9(10)$ & $0(0)$ & $5(8)$ & $6(6.4)$ & $4(13)$ \\
\hline Diabetes mellitus & $5(4)$ & $9(10)$ & $0(0)$ & $7(11)$ & $5(5)$ & 2 (6) \\
\hline
\end{tabular}

Data are shown as absolute value (percentage), mean \pm SD or median (25th-75th percentile).

${ }^{*} \mathrm{P}<0.05$ (compared with group with positive test and severity score $\leq 18$ ).

$\dagger \mathrm{P}<0.05$ (compared with group with positive test and severity score $>18$ ).

$\mathrm{BMI}$, body mass index.

In the positive test result group, the basic regression models showed that the risk of high symptom severity decreased with intake of 'legumes', and 'grains, bread and cereals' (OR below 1.0) as the most significant contributors. In the group with negative test results, the basic regression model showed that the risk of high symptom severity increased with the habitual intake of 'fats and oil', as well as with intake of 'hot peppers and sauce'. As the underlying health disorders for the group with negative tests are unknown, we cannot further discuss them.

Figure 1 shows the results on appetite score, food taste score and Bristol chart score. Patients with a positive SARS-CoV-2 test had lower appetite and food taste scores than patients with a negative SARS-CoV-2 test. The Bristol chart score was similar between the groups.

Table 4 Spearman's correlation analyses between symptom severity score and age (years) versus habitual frequency of food intake

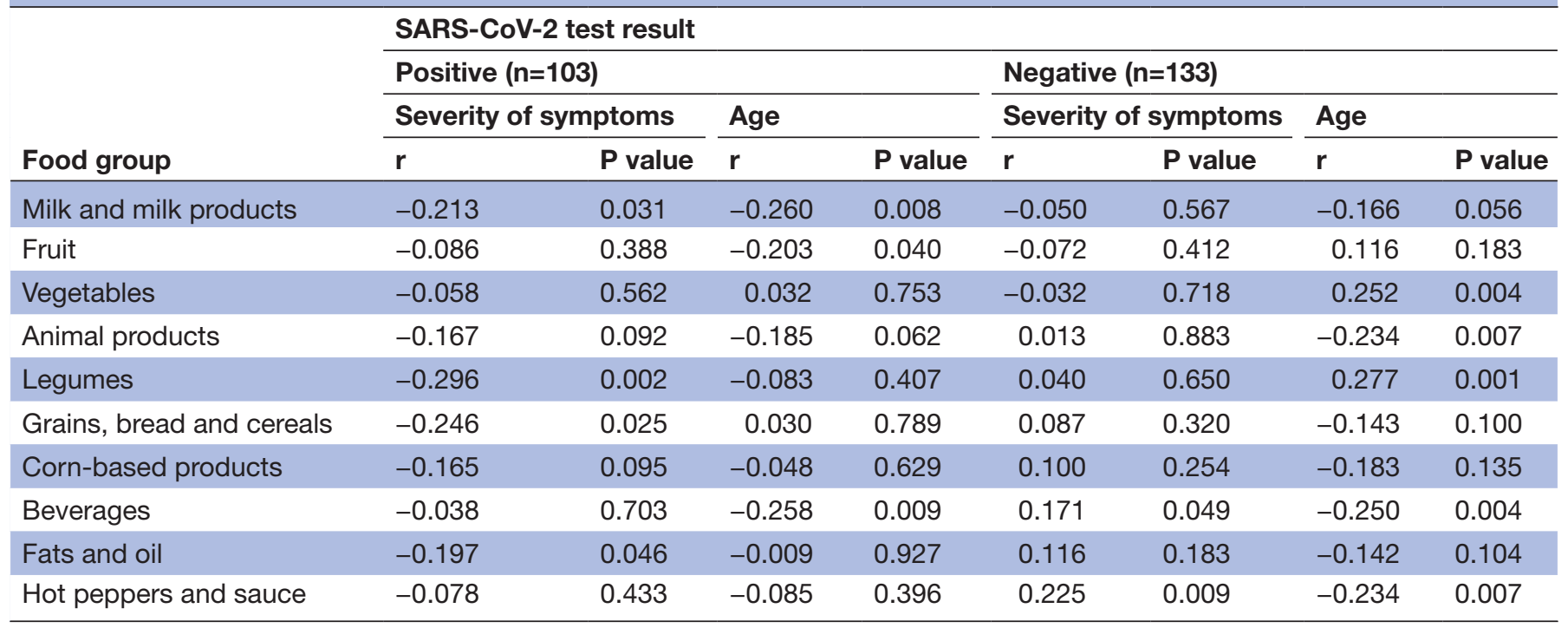


Table 5 Binary logistic regression analysis between symptom severity score $>18$ (as dependent variable) and frequency of food intake (as independent variable)

\begin{tabular}{|c|c|c|c|c|}
\hline \multirow[b]{3}{*}{ Food group } & \multicolumn{4}{|c|}{ SARS-CoV-2 test result } \\
\hline & \multicolumn{2}{|l|}{ Positive (n=103) } & \multicolumn{2}{|l|}{ Negative $(n=133)$} \\
\hline & Basic model & Multivariate model† & Basic model & Multivariate model† \\
\hline Fruit & 0.99 (0.96 to 1.03$)$ & 1.00 (0.96 to 1.03$)$ & 0.97 (0.95 to 1.02$)$ & 0.97 (0.94 to 1.01$)$ \\
\hline Vegetables & 0.99 (0.97 to 1.02$)$ & 1.00 (0.97 to 1.03$)$ & 0.99 (0.97 to 1.02$)$ & 1.00 (0.96 to 1.02$)$ \\
\hline Legumes & $0.87(0.76 \text { to } 0.99)^{\star}$ & $0.86(0.74 \text { to } 0.99)^{\star}$ & 1.00 (0.90 to 1.12$)$ & $1.04(0.92$ to 1.18$)$ \\
\hline Grains, bread and cereals & $0.92(0.86 \text { to } 0.98)^{\star \star}$ & $0.91(0.84 \text { to } 0.97)^{\star \star}$ & 1.03 (0.99 to 1.07$)$ & 1.03 (0.99 to 1.07$)$ \\
\hline Corn-based products & 0.97 (0.90 to 1.06$)$ & $0.98(0.90$ to 1.07$)$ & 1.04 (0.99 to 1.10$)$ & 1.04 (0.98 to 1.10$)$ \\
\hline Beverages & 0.99 (0.94 to 1.04$)$ & 0.99 (0.94 to 1.05$)$ & 1.03 (0.99 to 1.07$)$ & 1.03 (0.99 to 1.07$)$ \\
\hline Fats and oil & 0.95 (0.89 to 1.03$)$ & 0.95 (0.88 to 1.02$)$ & $1.06(1.00 \text { to } 1.12)^{*}$ & 1.06 (0.99 to 1.12$)$ \\
\hline
\end{tabular}

Results are shown as OR $(95 \% \mathrm{Cl})$.

${ }^{*} \mathrm{P}<0.05,{ }^{*} \mathrm{P}<0.01$.

†Multivariate models were adjusted for age, sex and occupation.

BMI had no correlations with symptom severity sum score in patients with a positive test $(\mathrm{r}=0.202, \mathrm{p}=0.069)$ and a negative test $(\mathrm{r}=0.103, \mathrm{p}=0.877)$. However, BMI had a significant correlation with age in patients with a positive test but no correlation in patients with a negative test, as shown in figure 2 .

\section{DISCUSSION}

In general, previous studies have shown that diets high in fibre, carbohydrates and nutrients can decrease the risk of respiratory infections, such as the common cold and pneumonia, and also shorten their duration. ${ }^{36}$ It is generally assumed that such diets can support the immune system by stimulating the production of antibodies and lymphocytes and by reduction of oxidative stress. Diet also changes the type and frequency of the commensal microbiota. There have been suggestions regarding the impact of diet on SARS-CoV-2 infections as a result of gut microbiota modulation. ${ }^{103738}$ Yeoh et $a l^{39}$ have shown that the gut microbiome composition could be significantly altered in patients with COVID-19 compared with individuals without COVID-19, irrespective of whether patients had received medication $(p<0.01)$. They have also demonstrated the associations between gut microbiota composition, cytokine levels and inflammatory markers in patients with COVID-19, suggesting that the gut microbiome make-up may be associated with COVID-19 severity. ${ }^{39}$

Our study showed that there are significant correlations between severity of symptoms and habitual food intake among outpatients with SARS-CoV-2 infection. Altogether, the relationship between long-term dietary components before infection and SARS-CoV-2 symptom severity appeared to be multifactorial. While symptom severity sum score had significant bivariate negative correlations with frequency of intake of 'milk and milk products', 'legumes', 'grains', 'bread and cereals', and 'fat and oils', the strongest negative correlation was obtained for legumes $(\mathrm{r}=-0.296, \mathrm{p}=0.002)$, table 4 . The subsequent multivariate regression analyses (table 5) confirmed that, after being adjusted by confounding variables, there was a significant association between having a high symptom severity score and the habitual frequency intake of 'legumes' and 'grains bread and cereals'.

These results suggest that long-term habitual intake of 'legumes', and 'grains, bread and cereals' food groups can be beneficial in protecting adults against the symptoms of SARS-CoV-2 infection. Interestingly, reliance on other food groups such as fruit and vegetables, which are frequently suggested as beneficial during COVID-19, did not appear to have a statistically significant impact on the severity of symptoms in the positive population.

Our observations are, in part, in agreement with previous studies on the role of diet in enhancing systemic immunity against SARS-CoV-2 infections. In a recent study, Kim $e t \mathrm{al}^{11}$ have shown that the severity of symptoms in patients with COVID-19 who followed a plant-based diet has been lower than those who reported following low-carbohydrate, high-protein diets. Altogether, people with a healthier nutritional status presented lower susceptibility to severe COVID-19. ${ }^{40}$

Natural milk and milk products are high in beneficial fats, and milk-based products such as natural yoghurt are made of beneficial bacteria. A new study has shown that natural milk contains biocomponents that are highly protective against COVID-19 infections. ${ }^{41}$ Dairy is a good source of branched-chain fatty acids (BCFAs). Animalbased studies have shown that BCFAs alter the microbiota composition in micro-organisms that use these fatty acids in cellular membranes. ${ }^{42}$ Because they are normal 

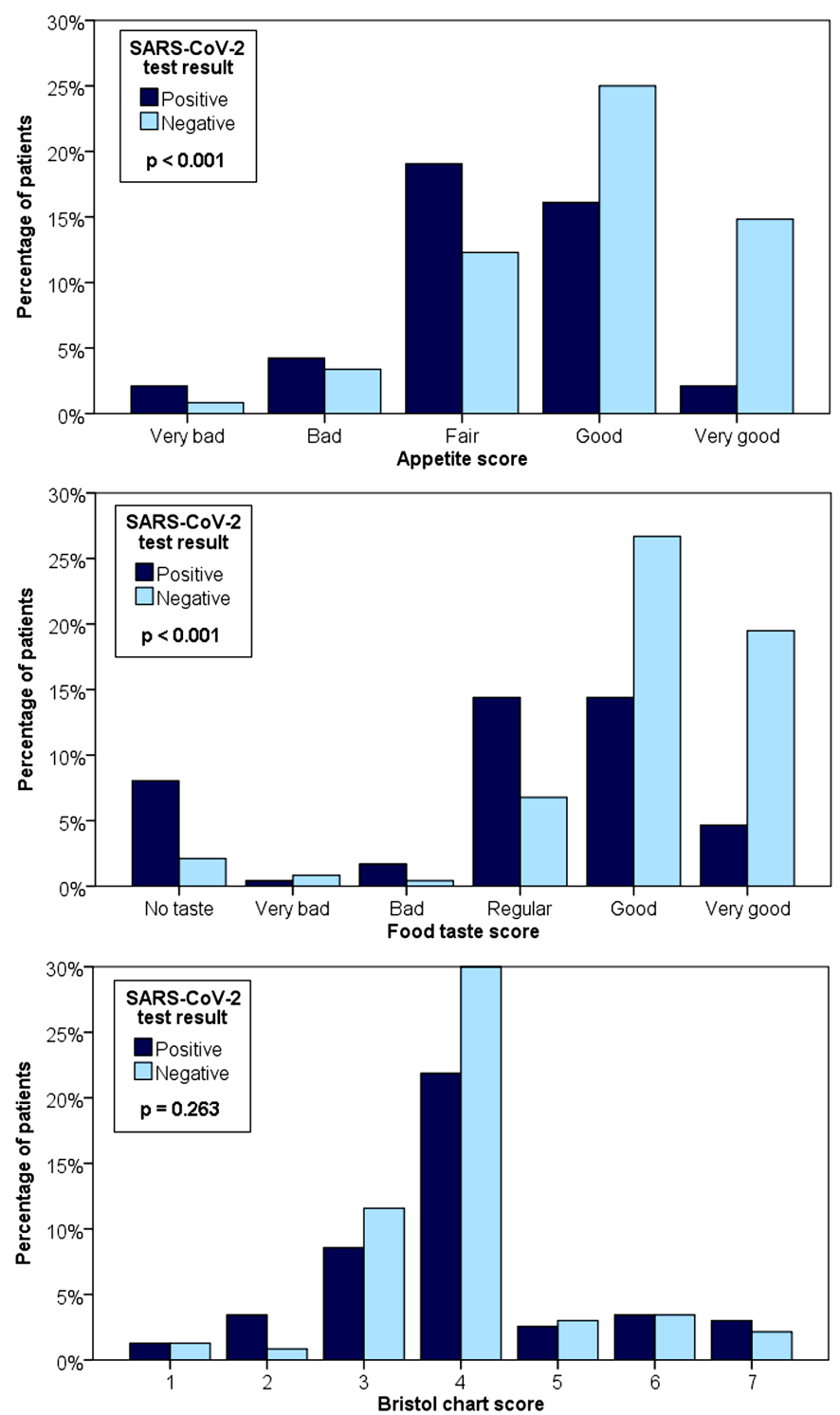

Figure 1 Appetite score, food taste score and Bristol chart score results.

constituents of the healthy human infant gut, these fatty acids could play a role in normal colonisation. ACE2 receptor is a key target of SARS-CoV-2. Peptides found in milk pose an ACE inhibitory activity. ${ }^{43}$ Probiotics such as Bifidobacteria and Lactobacillus which are found in dairy products are beneficial in building a resilient and diversified gut microbiota. ${ }^{37}$ Additionally, probiotics such as Lactobacillus acidophilus and L. casei which are found in natural yoghurt are suggested to boost systemic immunity against SARS-CoV-2 infection. ${ }^{37}$ In comparison, in our work, the effect of 'milk and milk products' and 'fats and oil' habitual intakes were inconclusive, since the association with symptom severity score was not significant after adjusting for the confounding variables (table 5).

A very important finding of this work was that patients with positive COVID-19 tests and mild symptoms had a high intake of legumes in particular, and grains, bread and cereals to a lesser extent. Legumes are among the most consumed food groups among the population of

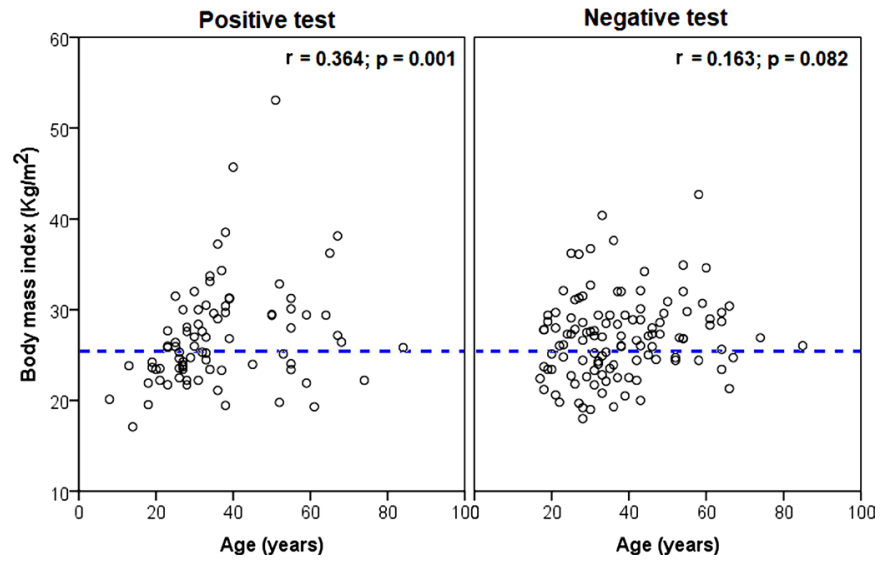

Figure 2 Scatter-dot plots of BMI as a function of age in the study participants. The dotted lines separate patients with normal BMI from overweight or obese patients. BMI, body mass index.

this study (who live in Mexico) and provide soluble fibre and amino acids. Legumes are a good source of branchedchain amino acids, which increase intestinal immunoglobulin level, improving the gut barrier. ${ }^{44}$ Non-digestible starch (known as resistant starch), mainly present in heattreated grains, is considered a significant part of dietary fibres in many countries including Mexico. It is known that resistant starch increases short-chain fatty acid (SCFA) production in the colon, ${ }^{44}$ including propionate, acetate and butyrate, resulting from the fermentation of undigested soluble dietary fibres by the gut microbiota. These are important immunomodulatory metabolites, and their role has been extensively explored in the gutlung axis. ${ }^{45}$ Portune $e t a l^{46}$ have reported an increase in beneficial bacteria such as Ruminococcus spp and Bifidobacterium spp due to a relative increase in dietary fibre, which is associated with enhanced systemic immunity. Plant-based fibre also has prebiotic effects, promoting the growth of bacteria that are associated with health benefits, such as Bifidobacterium spp and Lactobacillus spp. A fibre-rich diet modifies both the lung and gut microbiota composition and protects against allergic inflammation through increased circulating levels of SCFAs. ${ }^{47}$ Similarly, an increase in the population of Bifidobacterium and Lactobacillus was also seen among people on a bread-based diet. $^{48}$ In contrast, in populations with reduced polysaccharide intake, potentially opportunistic pathogens are increased, such as Escherichia coli and total Enterobacteriaceae. ${ }^{7}$ A recent study by Merino et $a l^{49}$ found that a dietary pattern characterised by healthy plant foods was associated with lower risk and severity of COVID-19

Yeoh $e t a l^{39}$ have shown that specific gut commensals with known immunomodulatory potential, including Faecalibacterium prausnitzii, Eubacterium rectale and Bifidobacteria, were under-represented in patients with COVID-19. The two most dominant bacterial species in the human colon are $F$. prausnitzii and E. rectale, contributing significantly to butyrate production. ${ }^{46}$ It is known that legumes, bread and cereals promote the presence of $F$. prausnitzii, E. 
rectale and Bifidobacteria, which produce SCFAs. Higher bifidobacterial counts and higher total SCFAs are related to greater intake of plant-based nutrients, such as vegetable proteins and polysaccharides. ${ }^{44}$

Interestingly, we found that the habitual intake of legumes and grains, bread and cereals food groups did not show any effect in outpatients with negative COVID-19 tests. This may indicate that the effect of these types of foods is only in COVID-19-positive patients and their habitual intake may not decrease symptom severity in other patients, such as those with the common cold or influenza. In a recent study, Gu et a $\bar{l}^{\tilde{D}^{0}}$ showed that the gut microbial composition of patients with COVID-19 was different from that of H1N1 patients and healthy controls. One of their findings was that the abundance of Prevotella, Ezakiella, Murdochiella and Porphyromonas was higher in the H1N1 group than in patients with COVID19. This is an observation that should be further explored in future studies.

This study was conducted in the Alvaro Obregon borough of Mexico City, Mexico. As such, habitual accessible food groups are limited to the region. There may be a limitation as food grouping includes regional foods. However, food groups definitions and categorisations might be different in other populations. This crosssectional investigation shows a correlation between food intake patterns and symptom severity, while it does not necessarily determine causality. Some confounders have been addressed, including age, sex and occupation. Nevertheless, other variables that could influence the outcomes of this work remain to be studied, for instance SARS-CoV-2 strain type and the genetic and immunological features of this population that might impact clinical features. Furthermore, individual characteristics and community behaviours may modify the perception of severity of symptoms and hence the search for diagnostic and treatment services.

In other studies, it has been observed that the nutritional quality of food diminished during the lockdown periods, ${ }^{51}$ as well as physical activity. ${ }^{52}$ However, this phenomenon could not be detected in our population due to lack of a previous comparison. Also, it is important to mention that the study was conducted before the dominance of the SARS-CoV-2 delta strain in Mexico, which may alter the outcomes. Although this is an open-population study, the clinic where the patients were treated offers medical assistance to mainly the inhabitants of 1 of the 16 boroughs located in Mexico City. Consequently, these findings may be different in other populations. The food patterns are specific to the population investigated, so the contribution of findings from this single study is limited and replicating the study findings in other populations is important. Finally, total caloric intake was not included in the analysis as we employed a non-quantitative FFQ.

In conclusion, the potential relationship between habitual intake of certain food groups and symptom severity in suspected SARS-CoV-2 infections was explored in 236 adults outpatients, with either positive or negative PCR test result. They attended an outpatient clinic for suspected COVID-19 and then answered a habitual FFQ. Out of 236 outpatients, diagnostic tests were positive for 103 and negative for 133. SARS-CoV2-positive outpatients showed a significant negative correlation between symptom severity and habitual frequency of intake of 'legumes', and 'grains, bread and cereals' food groups. As a result, it may be concluded that an increase in habitual frequency of intake of such food groups may decrease the severity of symptoms in those infected with SARS-CoV-2. This work can be potentially used as a guide for designing suitable diets during the COVID-19 pandemic and also for establishing a future vision that diet-based interventions may be explored for mitigating COVID-19 severity.

\section{Author affiliations}

${ }^{1}$ Centro Universitario de la Costa, Department of Medical Sciences, Universidad de Guadalajara, Puerto Vallarta, Mexico

${ }^{2}$ Chemical Engineering (Food Science and Technology), University of New South Wales, Sydney, New South Wales, Australia

${ }^{3}$ Centro de Salud Jalalpa el Grande, Secretaría de Salud de la Ciudad de México, Mexico City, Mexico

${ }^{4}$ Plan de Estudios Combinados en Medicina (PECEM), Facultad de Medicina, Universidad Nacional Autónoma de México, Mexico City, Mexico

${ }^{5}$ Instituto de Ciencias de la Salud, Universidad Autónoma del Estado de Hidalgo, Pachuca, Mexico

${ }^{6}$ Department of Electromechanical Instrumentation, Instituto Nacional de Cardiología Ignacio Chávez, Mexico City, Mexico

\section{Twitter Claudia Lerma @clermag}

Acknowledgements The authors thank Dr Victor Kawas-Bustamante and Dr Yesenia Anahi Camarillo-Cristobal for their helpful comments.

Contributors Conception and design: ES-R, KK-Z, HB and CL initiated the concept. $\mathrm{CL}$ had full access to all of the data in the study and takes responsibility for the integrity of the data and accuracy of the data analysis. Acquisition, analysis and/or interpretation of data: ES-R, KK-Z, HB, MC-J, CAG-B, PDL-P, AL and CL. Drafting of the manuscript: ES-R, KK-Z, HB, MC-J and CL. Critical revision of the manuscript: all authors. Statistical analysis: ES-R and CL. Administrative, technical or material support: MC-J, HB, CAG-B, PDL-P, AL and CL. Supervision: ES-R, CL and KK-Z. CL accepts all responsability for the work and/or the conduct of the study, have access to the data and controlled the decision to publish.

Funding The authors have not declared a specific grant for this research from any funding agency in the public, commercial or not-for-profit sectors.

Competing interests None declared.

Patient consent for publication Not required.

Ethics approval All procedures performed followed the ethical standards of the Research and Ethics Committee of the Instituto Nacional de Cardiología Ignacio Chávez (protocol number 21-1226), the Ethics Committee of the Universidad Autónoma del Estado de Hidalgo (protocol number 2021/34), and the 1964 Helsinki Declaration and its later amendments.

Provenance and peer review Not commissioned; externally peer reviewed. Data availability statement Data are available upon reasonable request.

Supplemental material This content has been supplied by the author(s). It has not been vetted by BMJ Publishing Group Limited (BMJ) and may not have been peer-reviewed. Any opinions or recommendations discussed are solely those of the author(s) and are not endorsed by BMJ. BMJ disclaims all liability and responsibility arising from any reliance placed on the content. Where the content includes any translated material, BMJ does not warrant the accuracy and reliability of the translations (including but not limited to local regulations, clinical guidelines, terminology, drug names and drug dosages), and is not responsible for any error and/or omissions arising from translation and adaptation or otherwise. 
Open access This is an open access article distributed in accordance with the Creative Commons Attribution Non Commercial (CC BY-NC 4.0) license, which permits others to distribute, remix, adapt, build upon this work non-commercially, and license their derivative works on different terms, provided the original work is properly cited, appropriate credit is given, any changes made indicated, and the use is non-commercial. See: http://creativecommons.org/licenses/by-nc/4.0/.

\section{ORCID iDs}

Kourosh Kalantar-Zadeh http://orcid.org/0000-0001-6109-132X

Claudia Lerma http://orcid.org/0000-0002-4679-7751

\section{REFERENCES}

1 Jenkins DJA, Kendall CWC, Augustin LSA, et al. Effect of legumes as part of a low glycemic index diet on glycemic control and cardiovascular risk factors in type 2 diabetes mellitus: a randomized controlled trial. Arch Intern Med 2012;172:1653-60.

2 Forman JP, Stampfer MJ, Curhan GC. Diet and lifestyle risk factors associated with incident hypertension in women. JAMA 2009;302:401-11.

3 Anderson DA, Shapiro JR, Lundgren JD, et al. Self-reported dietary restraint is associated with elevated levels of salivary cortisol. Appetite 2002;38:13-17.

4 Menon V, Kopple JD, Wang X, et al. Effect of a very low-protein diet on outcomes: long-term follow-up of the modification of diet in rena disease (MDRD) study. Am J Kidney Dis 2009;53:208-17.

5 Strachan DP, Powell KJ, Thaker A, et al. Vegetarian diet as a risk factor for tuberculosis in immigrant South London Asians. Thorax 1995;50:175

6 Vahid F, Rahmani D. Can an anti-inflammatory diet be effective in preventing or treating viral respiratory diseases? a systematic narrative review. Clin Nutr ESPEN 2021;43:9-15.

7 Singh RK, Chang H-W, Yan D, et al. Influence of diet on the gut microbiome and implications for human health. $J$ Transl Med 2017;15:73.

8 Wypych TP, Marsland BJ, Ubags NDJ. The impact of diet on immunity and respiratory diseases. Ann Am Thorac Soc 2017;14:S339-47.

9 Rodriguez-Morales AJ, Cardona-Ospina JA, Gutiérrez-Ocampo $\mathrm{E}$, et al. Clinical, laboratory and imaging features of COVID-19: a systematic review and meta-analysis. Travel Med Infect Dis 2020;34:101623.

10 Morais AHdeA, Aquino JdeS, da Silva-Maia JK, AHdA M, JdS $A$, et al. Nutritional status, diet and viral respiratory infections: perspectives for severe acute respiratory syndrome coronavirus 2 . $\mathrm{Br}$ J Nutr 2021;125:851-62.

$11 \mathrm{Kim} \mathrm{H}$, Rebholz CM, Hegde S. Plant-based diets, pescatarian diets and COVID-19 severity: a population-based case-control study in six countries. BMJ Nutrition, Prevention \& Health 2021:bmjnph2021-000272.

12 Rodriguez-Leyva D, Pierce GN. The impact of nutrition on the COVID-19 pandemic and the impact of the COVID-19 pandemic on nutrition. Nutrients 2021;13:1752.

13 Di Renzo L, Gualtieri P, Pivari F, et al. Eating habits and lifestyle changes during COVID-19 lockdown: an Italian survey. J Trans/ Med 2020;18:229.

14 Lamarche B, Brassard D, Lapointe A, et al. Changes in diet quality and food security among adults during the COVID-19related early lockdown: results from NutriQuébec. Am J Clin Nutr 2021;113:984-92.

15 Villapol S. Gastrointestinal symptoms associated with COVID-19: impact on the gut microbiome. Trans/ Res 2020;226:57-69.

16 Liu J, Cui M, Yang T, et al. Correlation between gastrointestinal symptoms and disease severity in patients with COVID-19: a systematic review and meta-analysis. BMJ Open Gastroenterol 2020;7:e000437.

17 Ardisson Korat AV, Willett WC, Hu FB. Diet, lifestyle, and genetic risk factors for type 2 diabetes: a review from the nurses' health study, nurses' health study 2 , and health professionals' follow-up study. Curr Nutr Rep 2014;3:345-54.

18 Zheng D, Liwinski T, Elinav E. Interaction between microbiota and immunity in health and disease. Cell Res 2020;30:492-506.

19 Janda L, Mihalčin M, Št’astná M. Is a healthy microbiome responsible for lower mortality in COVID-19? Biologia 2020:1-11.

$20 \mathrm{Kim} \mathrm{HS}$. Do an altered gut microbiota and an associated leaky gut affect COVID-19 severity? MBio 2021;12

21 David LA, Maurice CF, Carmody RN, et al. Diet rapidly and reproducibly alters the human gut microbiome. Nature 2014;505:559-63.
22 Williamson EJ, Walker AJ, Bhaskaran K, et al. Factors associated with COVID-19-related death using OpenSAFELY. Nature 2020;584:430-6.

23 Butler MJ, Barrientos RM. The impact of nutrition on COVID-19 susceptibility and long-term consequences. Brain Behav Immun 2020;87:53-4.

24 Sanmiguel C, Gupta A, Mayer EA. Gut microbiome and obesity: a plausible explanation for obesity. Curr Obes Rep 2015;4:250-61.

25 Batis C, Rodríguez-Ramírez S, Ariza AC, et al. Intakes of energy and discretionary food in Mexico are associated with the context of eating: mealtime, activity, and place. J Nutr 2016;146:1907S-15.

26 Abdulah DM, Hassan AB. Relation of dietary factors with infection and mortality rates of COVID-19 across the world. $J$ Nutr Health Aging 2020;24:1011-8.

27 Bousquet J, Anto JM, laccarino G, et al. Is diet partly responsible for differences in COVID-19 death rates between and within countries? Clin Transl Allergy 2020;10:16.

28 Kamyari N, Soltanian AR, Mahjub H, et al. Diet, nutrition, obesity, and their implications for COVID-19 mortality: development of a marginalized two-part model for Semicontinuous data. JMIR Public Health Surveill 2021;7:e22717.

29 Gao J, Quan L. Current status of diagnostic testing for SARSCoV-2 infection and future developments: a review. Med Sci Monit 2020;26:e928552.

30 Insituto de Diagnóstico y Referencia Epidemiológicos. Protocolo de bioseguridad y biocustodia para la toma y manejo de muestra en el laboratorio para la enfermedad respiratoria viral. Available: https:// www.gob.mx/cms/uploads/attachment/file/577831/Protocolo Bioseguridad_Biocustodia_Enfermedad_Viral_InDRE_V7 _ 09sep2020.pdf

31 INEGI, Encuesta Nacional de Salud y Nutrición (ENSANUT). Frecuencia de consumo de alimentos de adolescentes $Y$ adultos (12 años O más), 2019. Available: https://ensanut.insp.mx/encuestas/ ensanut2018/descargas.php

32 Pantilat SZ, O'Riordan DL, Dibble SL, et al. Longitudinal assessment of symptom severity among hospitalized elders diagnosed with cancer, heart failure, and chronic obstructive pulmonary disease. $J$ Hosp Med 2012;7:567-72.

33 Multanen J, Ylinen J, Karjalainen T, et al. Structural validity of the boston carpal tunnel questionnaire and its short version, the 6-Item CTs symptoms scale: a Rasch analysis one year after surgery. BMC Musculoskelet Disord 2020;21:609.

34 VanWormer JJ, Sundaram ME, Meece JK, et al. A cross-sectional analysis of symptom severity in adults with influenza and other acute respiratory illness in the outpatient setting. BMC Infect Dis 2014;14:231.

35 Parés D, Comas M, Dorcaratto D, et al. Adaptation and validation of the bristol scale stool form translated into the Spanish language among health professionals and patients. Rev Esp Enferm Dig 2009;101:312-6.

36 Calder PC. Nutrition, immunity and COVID-19. BMJ Nutr Prev Health 2020;3:74-92.

$37 \mathrm{Hu}$ J, Zhang L, Lin W, et al. Review article: probiotics, prebiotics and dietary approaches during COVID-19 pandemic. Trends Food Sci Technol 2021;108:187-96.

38 Kalantar-Zadeh K, Ward SA, et al. Considering the effects of microbiome and diet on SARS-CoV-2 infection: nanotechnology roles. ACS Nano 2020;14:5179-82.

39 Yeoh YK, Zuo T, Lui GC-Y, et al. Gut microbiota composition reflects disease severity and dysfunctional immune responses in patients with COVID-19. Gut 2021;70:698-706.

40 Briguglio M, Pregliasco FE, Lombardi G, et al. The malnutritional status of the host as a virulence factor for new coronavirus SARSCoV-2. Front Med 2020;7:146.

41 Arenas A, Borge C, Carbonero A, et al. Bovine coronavirus immune milk against COVID-19. Front Immunol 2021;12:637152.

42 Astrup A, Magkos F, Bier DM, et al. Saturated fats and health: a reassessment and proposal for food-based recommendations: JACC state-of-the-art review. J Am Coll Cardiol 2020;76:844-57.

43 Avery A. Can diet influence the COVID-19 mortality rate? Komp Nutr Diet 2021;1:16-18.

44 Aranda-Olmedo I, Rubio LA. Dietary legumes, intestinal microbiota, inflammation and colorectal cancer. J Funct Foods 2020;64:103707.

45 Enaud R, Prevel R, Ciarlo E, et al. The Gut-Lung axis in health and respiratory diseases: a place for inter-organ and inter-kingdom crosstalks. Front Cell Infect Microbiol 2020;10:9.

46 Portune KJ, Benítez-Páez A, Del Pulgar EMG, et al. Gut microbiota, diet, and obesity-related disorders-the good, the bad, and the future challenges. Mol Nutr Food Res 2017;61. doi:10.1002/ mnfr.201600252. [Epub ahead of print: 2009 2016]. 
47 Espírito Santo C, Caseiro C, Martins MJ, et al. Gut microbiota, in the halfway between nutrition and lung function. Nutrients 2021;13. doi:10.3390/nu13051716. [Epub ahead of print: 19 May 2021].

48 Cuervo A, Valdés L, Salazar N, et al. Pilot study of diet and microbiota: interactive associations of fibers and polyphenols with human intestinal bacteria. J Agric Food Chem 2014;62:5330-6.

49 Merino J, Joshi AD, Nguyen LH, et al. Diet quality and risk and severity of COVID-19: a prospective cohort study. Gut 2021;70:2096-104.
50 Gu S, Chen Y, Wu Z, et al. Alterations of the gut microbiota in patients with coronavirus disease 2019 or H1N1 influenza. Clin Infect Dis 2020;71:2669-78.

51 Marty L, de Lauzon-Guillain B, Labesse M, et al. Food choice motives and the nutritional quality of diet during the COVID-19 lockdown in France. Appetite 2021;157:105005.

52 Knuppel A. Diet, lifestyle, and livelihoods during coronavirus disease 2019 (COVID-19)-related lockdowns and the value of web-based nutrition studies. Am J Clin Nutr 2021;113:763-4. 